\title{
Thyroid function, autoimmunity and nodules in hematological malignancies
}

${ }^{1}$ Department of Human Pathology, University of Messina, Messina, Italy 2 Department of Biomedical Sciences and Morphological and Functional Images, University of Messina, Messina, Italy

${ }^{3}$ Department of Clinical and Experimental Medicine, University of Messina, Messina, Italy ${ }^{4}$ Master Program on Childhood, Adolescence and Women's Endocrine Health, University of Messina, Messina, Italy ${ }^{5}$ Interdepartmental Program of Molecular \& Clinical Endocrinology, and Women's Endocrine Health, University Hospital, Messina, Italy

\author{
Correspondence to: \\ Alessandro Sindoni \\ Dipartimento di Scienze Biomediche \\ e delle Immagini Morfologiche \\ e Funzionali, U.O.C. di Medicina \\ Nucleare, AOU Policlinico "G. \\ Martino", Pad. E Piano Terra, Via \\ Consolare Valeria \\ 98125 - Messina, Italy. \\ alessandrosindoni@alice.it \\ Received on Jan/1/2015 \\ Accepted on Mar/30/2015
}

DOI: 10.1590/2359-3997000000044

\author{
Patrizia Mondello', Alessandro Sindoni ${ }^{2}$, Vincenzo Pitini', \\ Claudio Scisca', Giuseppe Altavilla', Salvatore Benvenga ${ }^{3,4,5}$
}

\begin{abstract}
Objective: Hematological malignancies encompass a large spectrum of disease entities whose treatment by chemo/radiotherapy could lead to thyroid complications. To the best of our knowledge, no study has simultaneously addressed thyroid function, autoimmunity and nodularity. Therefore, we decided to conduct one. Materials and methods: We evaluated 82 Caucasian patients (36 women and 46 men), who were treated at our Oncology division for hematological malignancies (multiple myeloma, chronic myeloid leukemia, chronic lymphatic leukemia, non-Hodgkin lymphoma and polycythemia vera) and compared them with a control group of 104 patients. Patients who had received or were receiving external head/neck radiotherapy were excluded. All oncological patients and control individuals underwent thyroid ultrasonography and thyroid function and autoimmunity tests. Results: A lower prevalence of enlarged thyroid and nodules were found in patients with respect to controls. The rate of thyroid nodules was the highest in multiple myeloma and polycythemia vera, and the lowest in chronic lymphatic leukemia. Non-Hodgkin lymphoma patients had the smallest thyroid nodules while men with multiple myeloma the biggest ones. No patient had hypothyroidism, while $5.6 \%$ of patients had subclinical hyperthyroidism. In contrast, within the control group the rates of hypothyroidism and hyperthyroidism, overt and subclinical, were $3.8 \%, 20.2 \%, 0 \%$ and $0 \%$ respectively. Moreover, the overall rate of thyroid autoantibody positiveness in patients was significantly lower than controls. Conclusion: In our experience, we found a significantly lower prevalence of thyroid abnormalities in hematologic patients who underwent chemotherapy, but not radiotherapy, with respect to controls. Arch Endocrinol Metab. 2015;59(3):236-44
\end{abstract}

Keywords

Hematological malignancies; thyroid dysfunction; thyroid autoimmunity; thyroid nodules

\section{INTRODUCTION}

$\mathrm{H}$ ematological malignancies encompass a spectrum of heterogeneous disease entities with different epidemiology and whose classification has evolved dramatically into highly-specific disease subtypes of lymphoid malignancie (LM) and myeloid malignancie (1). In Europe, age-standardized incidence rates are 24.5 per 100000 for LMs and 7.55 per 100000 for MMs (2). The most common LMs are plasma cell neoplasms (4.62 per 100000), small B-cell lymphocytic lymphoma/chronic lymphatic leukemia (3.79 per $100000)$, diffuse B-cell lymphoma (3.13 per 100000$)$, and Hodgkin's lymphoma (2.41 per 100000$)$ (3). The most common myeloid malignancies are acute myeloid leukemia (2.96 per 100000), other myeloproliferative neoplasms (1.76 per 100000), and myelodysplastic syndrome (1.24 per 100000) (2).
Depending on the type of hematological malignancies, treatment consists in the administration of chemotherapy with or without radiotherapy. The chemotherapeutic schemes include alkylating agents, anthracyclines, nucleosides analogues, monoclonal antibodies, differentiating agents, epigenetic drugs, proteosome inhibitors, immunomodulatory drugs (IMiDs) and tyrosine kinase inhibitors (TKIs) (3). IMiDs (such as thalidomide and lenalidomide, which are used in multiple myeloma and non-Hodgkin lymphoma) and TKIs (such as imatinib, nilotinib and dasatinib, which are used in chronic myeloid leukemia) have also antiangiogenic properties (3). Among side effects of IMIDs and TKIs, alteration of thyroid function and triggering of thyroid autoimmunity has been reported (4-13). Side effects on the thyroid caused by head and neck radiotherapy include altered function and development of nodules that are at greater risk of being malignant (14). 
Thyroid lymphomas are rare malignancies and so are thyroid plasmacytomas (15). Primary thyroid lymphoma is associated with Hashimoto's thyroiditis (HT) in 40 to $80 \%$ of cases, and HT may precede thyroid lymphoma by 20 to 30 years $(15,16)$. Thyroid plasmacytoma anticipates multiple myeloma in up to onethird of cases (15).

Thyroid investigations in patients with hematological disorders have essentially focused on the thyroid complications ensuing from chemotherapy and/or external irradiation (4-10,14,17-28). Because no study has simultaneously taken care of all clinically relevant thyroid aspects (namely, function, autoimmunity and nodules), we have conducted such a study on hematoncologic patients excluding those who had been treated with external irradiation.

\section{MATERIALS AND METHODS}

\section{Patients' group}

We retrospectively evaluated 82 consecutive patients (36 women [F], 46 men [M]) admitted to our Oncology division for the management of the malignancies specified below. Criteria for entry were: a) living in our island (Sicily); b) treatment with chemotherapy only, and with a minimum of three years (36 months) from the beginning of chemotherapy. Their age at time of first visit was $64.5 \pm 12.2$ years (median: 66 ; range $34-83$ ), precisely $64.3 \pm 10$ years (median, 66; range 44-82) in women, and $64.2 \pm 13.5$ years (median, 65; range $34-83$ ) in men. Age of patients in the five oncologic subgroups specified below was similar, as analyzed by ANOVA (Df $=4, \mathrm{P}=0.46$; data not shown). Hematological malignancies were as follows: multiple myeloma $(\mathrm{MM}), \mathrm{n}=$ 22 ( $10 \mathrm{~F}$ and $12 \mathrm{M}$; 2 women had a known diagnosis of thyroid nodules 10 and 15 years earlier); chronic myeloid leukemia (CML), n = 8 (2 F and $6 \mathrm{M} ; 2$ men were thyroidectomized 3 and 7 years earlier because of a multinodular goiter); chronic lymphatic leukemia (CLL), $\mathrm{n}$ $=4(0 \mathrm{~F}$ and $4 \mathrm{M})$; non-Hodgkin lymphoma (NHL), $\mathrm{n}=36(20 \mathrm{~F}$ and $16 \mathrm{M}$; 4 women had nodular goiter diagnosed 5 to 10 years earlier; 1 man had a 2 -year history of antithyroid drug-treated Graves' disease and 1 man had a 7-year history of HT that was being treated with levothyroxine); polycythemia vera (PV), $\mathrm{n}=12$ patients $(4 \mathrm{~F}$ and $8 \mathrm{M})$. Patients underwent the following anticancer treatments: thalidomide $(\mathrm{n}=10 ; 4 \mathrm{~F}$ and 6 $\mathrm{M})$ or lenalidomide $(\mathrm{n}=12 ; 6 \mathrm{~F}$ and $6 \mathrm{M})$ for $\mathrm{MM}$, imatinib $(\mathrm{n}=6 ; 2 \mathrm{~F}$ and $4 \mathrm{M})$ and nilotinib $(\mathrm{n}=2 ; 0 \mathrm{~F}$ and $2 \mathrm{M}$ ) for CML, rituximab for CLL ( $\mathrm{n}=4$, all males) and NHL $(\mathrm{n}=36 ; 20 \mathrm{~F}$ and $16 \mathrm{M})$, interferon $(\mathrm{n}=8$; $4 \mathrm{~F}$ and $4 \mathrm{M})$ and oncocarbide $(\mathrm{n}=4 ; 0 \mathrm{~F}$ and $4 \mathrm{M})$ for $\mathrm{PV}$. Time interval between the beginning of treatment and thyroid control was $4.3 \pm 1.2$ years $(51.6 \pm 14.4$ months; median 50; range 37-65) for IMIDs, $5.7 \pm 1.8$ years $(68.4 \pm 21.6$ months; median: 71 ; range $45-89)$ for TKIs, $4.5 \pm 1.0$ years $(54 \pm 12$ months; median: 52 ; range 41-65) for rituximab, $4.9 \pm 1.5$ years $(58.8 \pm 18$ months; median: 60; range 40-76) for interferon and $5.7 \pm 1.4$ years $(68.4 \pm 16.8$ months; median: 73 ; range 51-85) for oncocarbide.

\section{Control group}

This group consisted of 104 consecutive Caucasian persons (69 women, 35 men), all unrelated to the patients in the study group, who had been observed during the local Thyroid Awareness Week campaigns (typically at the end of May) or who sought consultation at the endocrine division of our university hospital, and whose data were retrospectively collected. Due to the well known prevalence of thyroid diseases in women (and therefore greater interest in screening by women compared to men), it was, and is, very hard to collect a control group with a slight predominance of males over females as in the patient group. Nevertheless, age of controls were comparable to patients, both in the whole cohort $(\mathrm{n}=104,61.5 \pm 12.6$, median 64 , range $34-81 ; \mathrm{P}=0.19$ vs. patients $)$, in women $(\mathrm{n}=69,61.1 \pm$ 13.4, median 65, range 41-81, $\mathrm{P}=0.39$ ) and in men (n $=35,62.3 \pm 10.7$, median 64 , range $34-80, \mathrm{P}=0.29$ ).

Control individuals recruited from either of the aforesaid sources were observed within three years from observation of the patients. The control individuals had to meet the following criteria: (a) to live in Sicily; (b) to have neither familial nor personal history of thyroid disease (including use of nonthyroid drugs that are known to alter thyroid volume and/or function, or induce thyroid autoimmunity); (c) to have no personal history of past or current malignancy; (d) to have no personal history of autoimmune diseases which would have favoured co-occurrence of clinically silent autoimmune thyroid disease (AITD). Concerning controls recruited at the endocrine division, they are equivalent to those examined (clinically and ultrasonographically) during the aforementioned local campaigns in terms of reasons for observation. Indeed, controls recruited at the endocrine division were individuals who had self-prescribed 
thyroid echography and the panel of biochemical thyroid tests (serum thyrotropin [TSH], free thyroxine [FT4], free triiodothyronine [FT3], thyroglobulin autoantibodies $[\mathrm{TgAb}]$, thyroperoxidase autoantibodies [TPOAb]) just as a part of a more general screening or because impressed by articles in websites, newspapers/magazines and/or broadcasts on television dealing with thyroid diseases. Thus, after having performed those investigations, they came to our observation for advice. The same panel of thyroid biochemical tests in individuals observed during the campaign was either self-prescribed in preparation for the visit and associated with thyroid ultrasonography or was performed later to complete the thyroid check-up. Because of no intervention involved, there was no need for approval by an ad hoc Ethics Committee. Written informed consent was obtained from all subjects. This work conforms the provisions of the Declaration of Helsinki.

\section{Biochemical assays}

For the purposes of our investigation, all oncological patients and control individuals had thyroid function tests (serum TSH, FT3 and FT4) and thyroid autoimmunity tests (serum $\mathrm{TgAb}$ and TPOAb) performed in the same laboratory with the same corresponding kits by Roche Diagnostics, which are based on electroluminescence. Reference ranges are 0.27-4.20 mU/L (TSH), 3.0-6.8 pmol/L (equivalent to $2.0-4.4 \mathrm{pg} / \mathrm{mL}, \mathrm{FT} 3$ ), 12-22 pmol/L (equivalent to 9.3-17.1 pg/mL, FT4), 0-115 U/mL (TgAb) and 0-34 U/mL (TPOAb).

As per standard criteria, the diagnosis of hypothyroidism relied on serum TSH and FT4, while the diagnosis of hyperthyroidism relied on serum TSH and thyroid hormones (FT3, FT4 or both). Patients were defined overtly hypothyroid when serum TSH was above $4.2 \mathrm{mU} / \mathrm{L}$ and FT4 below $12 \mathrm{pmol} / \mathrm{L}$, and subclinically hypothyroid when serum TSH was above 4.2 $\mathrm{mU} / \mathrm{L}$ and FT4 normal. Patients were defined overtly hyperthyroid when serum TSH was below $0.27 \mathrm{mU} / \mathrm{L}$ and FT3 and/or FT4 above their corresponding upper normal limits, and subclinically hyperthyroid when only TSH was abnormal (below $0.27 \mathrm{mU} / \mathrm{L}$ ). As reported previously, autoimmune thyroiditis was considered present if either condition was met: (i) increased serum levels of one or both thyroid autoantibodies regardless of the thyroid function and thyroid ultrasonography (see below); (ii) thyroid ultrasonography pattern of inflammation regardless of thyroid autoantibodies and thyroid function (29).

\section{Thyroid sonography}

Thyroid sonography was performed at the endocrine division, because the instrument available and equipped with a 7.5-10.0 MHz linear transducer at this division (Logiq by General Electric) is the same as the one used for all individuals in the control group. The thyroid parameters evaluated were volume, echo-texture, vascularization, nodules. Thyroid volume was calculated, as is typical, by summing the volume of each lobe using the ellipsoid formula; in this formula, the three diameters (that is, length, width and depth are multiplied, and the product multiplied by 0.52 ). Thyroid echo-texture is a fundamental feature to judge if thyroid inflammation is present. If inflammation exists, then, regardless of thyroid volume, the pattern is one of diffuse and dyshomogeneous hypoechogeneity with or without pseudonodules. The number, maximum diameter and ultrasonographic characteristics of all nodules were noted. Following conventional practice, thyroid nodules were defined micronodules if their maximum diameter was 10 millimeters at most. Thyroid pseudonodules, which are encountered frequently in an inflamed thyroid, were not counted as nodules.

\section{Statistical analyses}

Unless otherwise stated, data are reported as mean \pm SD and median. Differences between means \pm SD (continuous variables) were handled by analysis of variance (ANOVA) or, if lacking Gaussian distribution, by the Wilcoxon test. Variables with non-Gaussian distribution were serum TSH, TgAb, TPOAb and maximum diameter of thyroid nodules. Differences between proportions (categorical variables) were handled by the chi-squared test. For any statistical comparison, which was always two-tailed, a $P$ value of less than 0.05 was considered statistically significant. $\mathrm{P}$ values between 0.05 and 0.10 were considered borderline significant.

\section{RESULTS}

\section{Biochemical thyroid data}

As stated above (see Patients and Methods), 10/82 patients (12.2\%) had previously experienced thyroid disease and were therefore excluded from further evaluation. In these 10 patients, endocrine diagnoses were thyroid nodule(s) (n = 8; 2 with MM, 2 with CML and 4 with NHL) and AITD ( $\mathrm{n}=2$ [1 with Graves' 
disease and 1 with HT]; both with NHL). Considering the known predominance of AITD in females, it is noteworthy that in the NHL subgroup two of the AITD concerned men $(2 / 16=12.5 \%)$ and none of the women $(0 / 20)$. In contrast to the patients' group, none of the persons in the control group had previously known thyroid disease, as this was an exclusion criterion.

Biochemical thyroid data in the 72 patients and 104 controls are summarized in figure 1 . When biochemical data were handled as categorical variables, no patient had hypothyroidism (either overt or subclinical), and no patient had overt hyperthyroidism. Subclinical hyperthyroidism was observed only in $5.6 \%$ of patients, all males and all belonging to the multiple myeloma subgroup. In these four patients, FT4 was in the upper normal third (18.7 to $19.6 \mathrm{pmol} / \mathrm{L}$ ) and FT3 was in the lower or middle third $(4.1$ to $4.5 \mathrm{pmol} / \mathrm{L})$, suggesting that the low T3 syndrome associated with the nonthyroid illness (NTI) status might have contributed to the FT4-oriented as opposed to the FT3-oriented subclinical hyperthyroidism. This biochemical picture will be discussed further under the Discussion in view of some literature $(5,30,31)$. Thus, of the three hormones measured, only serum TSH was abnormal, and it was so because it was decreased in $5.6 \%$ of patients. In contrast, within the control group the rates of overt hypothyroidism, subclinical hypothyroidism, overt hyperthyroidism or subclinical hyperthyroidism were $3.8 \%$ $\left(\chi^{2}=2.83, \mathrm{P}=0.09\right.$ vs. $0 \%$ in the malignancy group $)$, $20.2 \%\left(\chi^{2}=16.51, \mathrm{P}<0.0001\right.$ vs. $\left.0 \%\right), 0 \%(\mathrm{P}=1.0$ vs. $0 \%)$ or $0 \%\left(\chi^{2}=5.91, \mathrm{P}=0.015\right.$ vs. $\left.5.6 \%\right)$, respectively.

When biochemical data were dealt upon as continuous variables, statistical differences between means \pm SD were observed for TSH and FT3. Difference in TSH was accounted for by the high rate of overt or subclinical thyroid hypofunction in the controls. Accordingly, once these hypothyroid subjects were excluded, serum TSH concentrations in controls were no longer statistically different from patients. Maintaining the exclusion of the confounding variable of thyroid failure, serum FT4 was not different from patients, while serum FT3 was greater $(\mathrm{P}=0.0002 ; \mathrm{P}=0.0004$ in women and $\mathrm{P}$ $=0.07 \mathrm{in} \mathrm{men})$. The lower concentration of serum FT3 in patients was expected, considering that malignancies are one of the causes of the adaptive low T3 syndrome (also known as euthyroid sick syndrome or nonthyroidal illness syndrome) (32).

Concerning thyroid autoantibodies, only TPOAb were increased, and only in men of the NHL subgroup.
This overall rate of $2.8 \% \mathrm{TPOAb}$ positiveness contrasts sharply with the equivalent overall rate of $25.0 \%$ in the control group $\left(\chi^{2}=15.70, \mathrm{P}<0.0001\right)$. When genders are analyzed separately, TPOAb positiveness was $4.8 \%$ in male patients and $0 \%$ in female patients, again differing from the corresponding rate of $22.8 \%\left(\chi^{2}=5.53, \mathrm{P}=\right.$ $0.019)$ and $26.1 \%\left(\chi^{2}=9.56, \mathrm{P}=0.002\right)$ in controls. For $\mathrm{TgAb}$, rates were $0 \%$ in the patient group, which contrasts with the rate of $30.0 \%$ in controls $\left(\chi^{2}=26.05, \mathrm{P}\right.$ $<0.0001)$. In male controls and female controls, TgAb positiveness rate was $22.8 \%\left(\chi^{2}=10.71, \mathrm{P}=0.0011\right)$ and $33.3 \%\left(\chi^{2}=13.03, \mathrm{P}=0.0003\right)$, respectively. Differences in rates of TPOAb and $\mathrm{TgAb}$ remained significant after having excluded patients with hypothyroidism.

\section{Ultrasonographic thyroid data}

These data are summarized in figure 2 . The rates of hypertrophic or hypothrophic thyroid were $6.0 \%$ or $0 \%$, respectively, which compare with the corresponding rates of $44.2 \%\left(\chi^{2}=31.29, \mathrm{P}<0.0001\right)$ or $6.7 \%\left(\chi^{2}=5.05\right.$, $\mathrm{P}=0.025)$ in the control group. Enlarged thyroid (that is, goiter) was detected only in patients with MM (10\%) or PV (17\%). Considering genders separately, these rates were due to the female gender. Indeed, abnormal size of thyroid gland was found only in $2 / 8(25 \%)$ of women with $\mathrm{MM}$ and $2 / 4$ women $(50 \%)$ with PV.

Overall, evidence of thyroiditis was noted in $8.3 \%$ of patients compared with $67.3 \%$ of controls $\left(\chi^{2}=60.31\right.$, $\mathrm{P}<0.0001$ ) (Figure 2). Particularly, the rate in women was $13.3 \%$ vs. $72.5 \%\left(\chi^{2}=29.49, \mathrm{P}<0.0001\right)$, and the rate in men $4.8 \%$ vs. $57.1 \%\left(\chi^{2}=25.67, \mathrm{P}<0.0001\right)$. Sonographic signs of thyroiditis were detected only in MM (10\%) and NHL (13\%), the latter featuring the highest frequency $(25 \%$, in women). In the myeloma subgroup, men outnumbered women ( $17 \%$ vs. $0 \%)$, whereas the opposite occurred in the NHL subgroup ( $13 \%$ in men vs. $25 \%$ in women).

The rate of thyroid nodules was $47.2 \%$ in patients and $81.7 \%$ in controls $\left(\chi^{2}=25.67, \mathrm{P}<0.0001\right)$; the rate in women was $60.0 \%$ vs. $79.8 \%\left(\chi^{2}=4.20, \mathrm{P}=0.040\right)$ and $38.1 \%$ vs. $85.7 \%$ in men $\left(\chi^{2}=18.0, \mathrm{P}<0.0001\right)$ (Figure 2$)$. The average number of nodules per thyroid (and therefore per person) was $2.9 \pm 1.9$ in patients, compared with $3.4 \pm 2.3$ in controls $(\mathrm{P}=0.25$, by the Wilcoxon test); it was $3.7 \pm 2.2$ in women $(3.4 \pm 2.4$ in control women, $\mathrm{P}=0.52$, by the Wilcoxon test) and $2.0 \pm 0.9$ in men $(3.4 \pm 2.1$ in control men, $\mathrm{P}=0.015$, by the Wilcoxon test). 

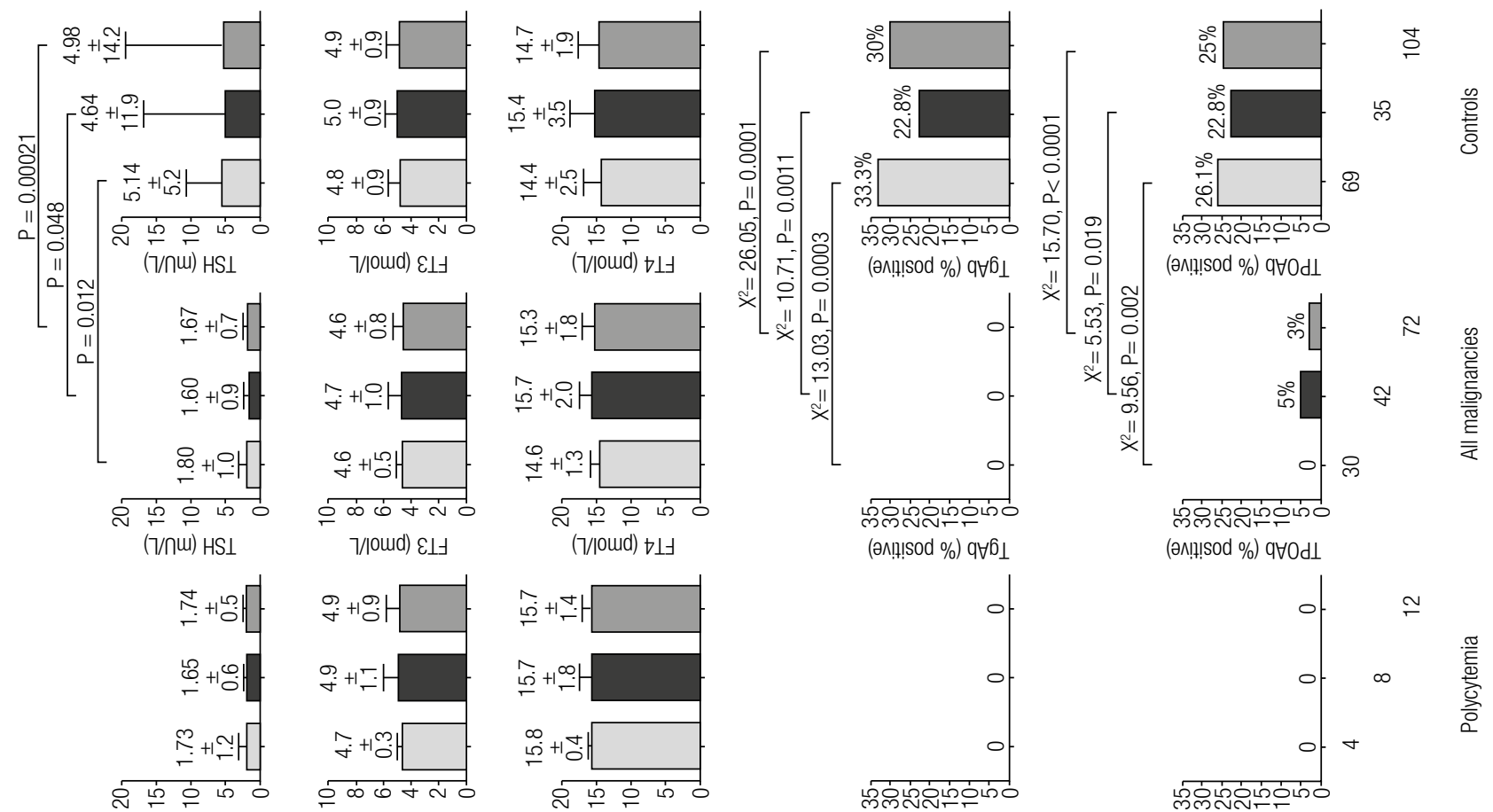

$(\mathrm{7} / \mathrm{nW}) \mathrm{HS \perp}$

$7 / / 0 u d) \varepsilon \perp \dashv$

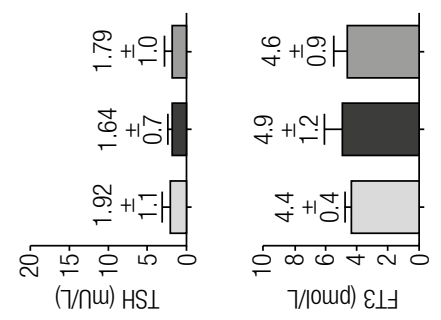

(7//oudd) $t+-$

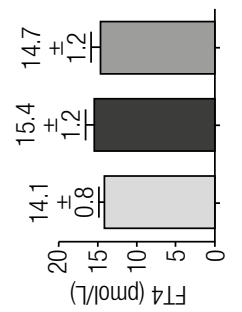

(әм!!!
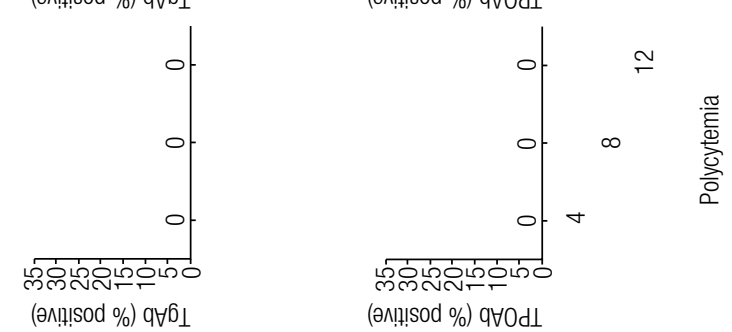

(әn!!!!sod \%) q $\forall 0 d \perp$

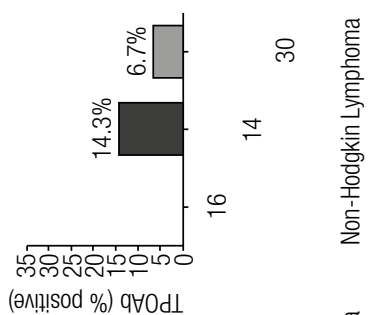

(әм!!!

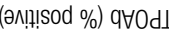
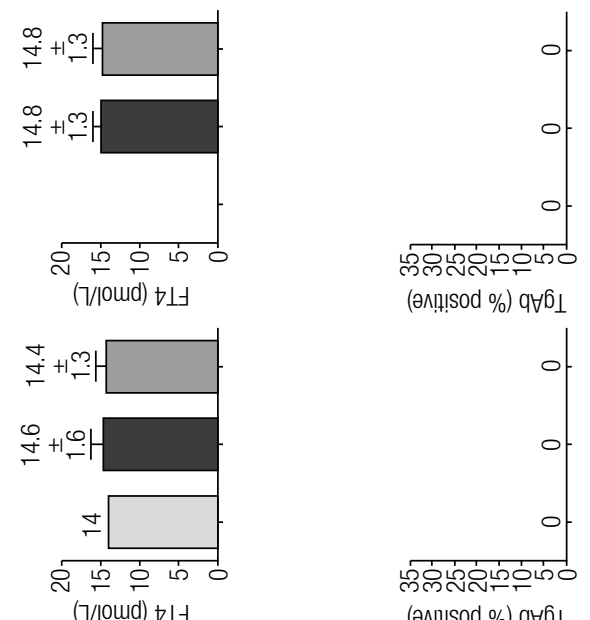

(วN!!!IOd \%) $9 \forall 6 \perp$

(әм!̣!!sod \%) q $\forall 0 \mathrm{d \perp}$

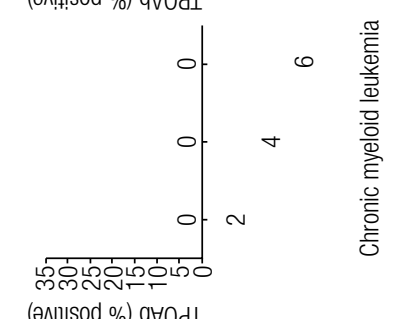

(әм!̣!ISOd \%) q $\forall 0 \mathrm{dI}$
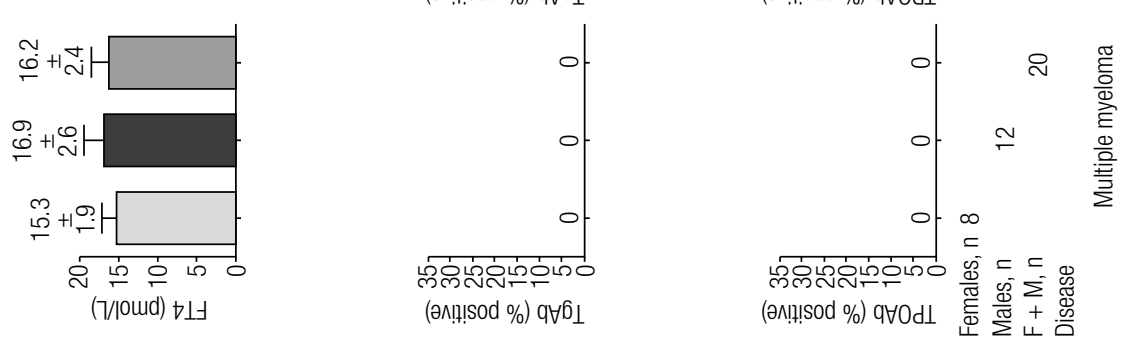

(әNI!ISOd \%) q甘61

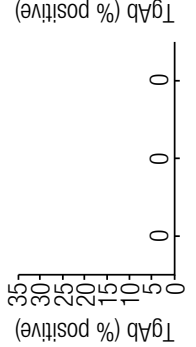

Figure 1. Serum thyroid function tests and thyroid autoantibodies in patients, excluding those with previously known thyroid diseases, and controls (none of whom had previously known thyroid disease). 

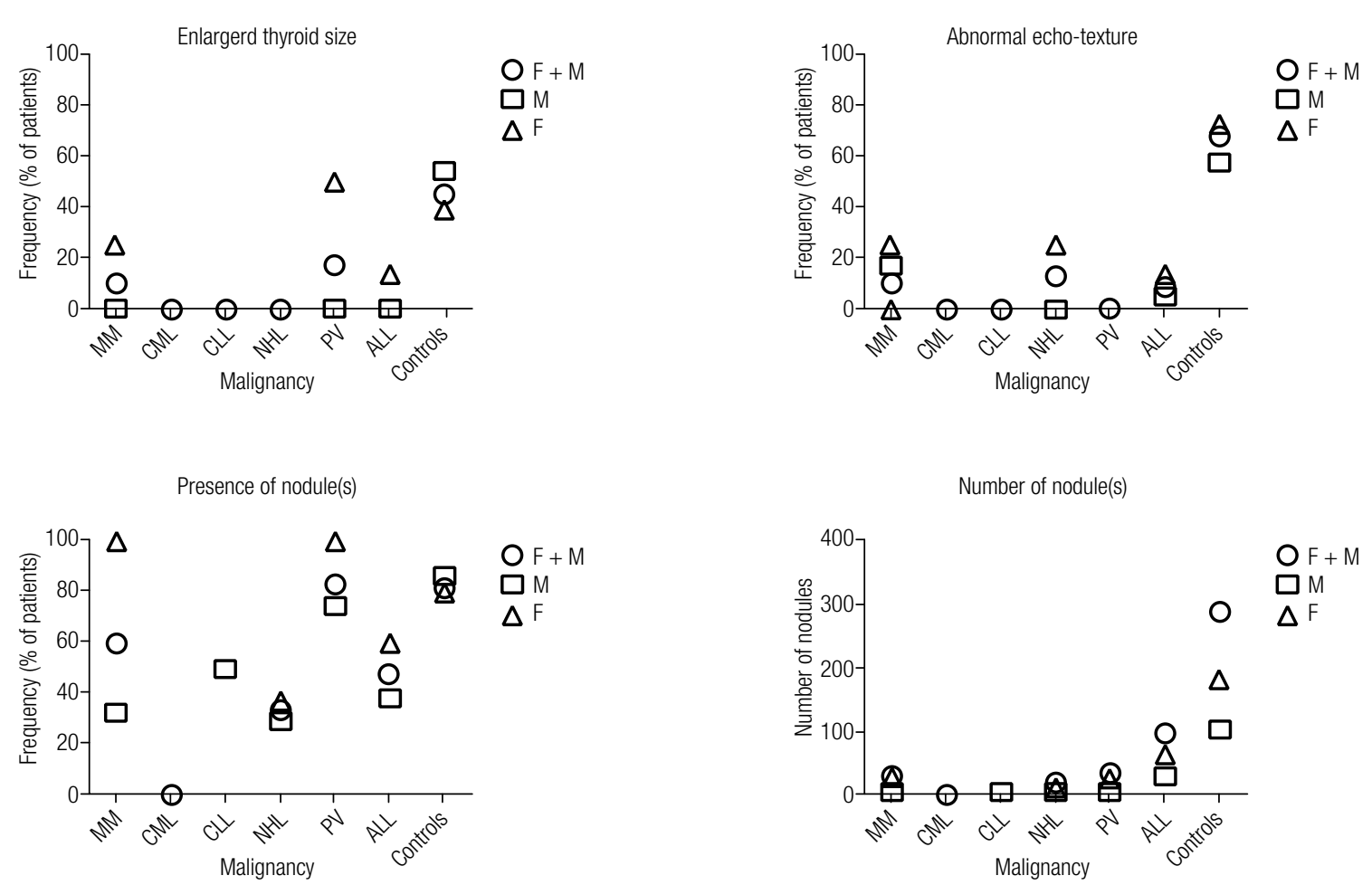

Figure 2. Thyroid sonography in patients, excluding those with previously known thyroid diseases, and controls (none of whom had previously known thyroid disease). MM: multiple myeloma; CML: chronic myeloid leukemia; CLL: chronic lymphatic leukemia; NHL: non-Hodgkin lymphoma; PV: polycythemia vera.

The maximum diameter of nodules averaged $8.1 \pm$ 5.5 [median 6.5 ] $\mathrm{mm}$ in patients, compared with 11.7 $\pm 9.1[$ median 8.3$] \mathrm{mm}$ in controls $(\mathrm{P}=0.0001$ by the Wilcoxon test); it was $8.4 \pm 6.1$ [median 6.2 ] $\mathrm{mm}$ in women $(11.2 \pm 9.2$ [median 8$]$ in control women, $\mathrm{P}=$ $0.015)$ and $7.6 \pm 3.9$ [median 6.6] $\mathrm{mm}$ in men $(12.8 \pm$ 8.6 [median 10] in control men, $\mathrm{P}=0.001$ ) (Figure 3). Because means \pm SD of the max diameter of nodules in the CLL and NHL groups were similar, they were pooled $(5.0 \pm 1.9[$ median 4.8$]$; men $=4.9 \pm 2.1[$ median 4.6]; women $=5.2 \pm 1.6$ [median 5.3]). Differences were statistically significant compared to the MM group, precisely: $8.8 \pm 6.6 \mathrm{~mm}$ of the 32 nodules $(\mathrm{P}=$ 0.0025 by the Wilcoxon test), and $11.1 \pm 4.1 \mathrm{~mm}$ of the 8 nodules in men $(\mathrm{P}=0.0044$, by the Wilcoxon test $)$; however, difference was insignificant compared to 8.0 $\pm 7.1 \mathrm{~mm}$ of the 24 nodules in women $(\mathrm{P}=0.26$ by the Wilcoxon test). In the corresponding comparison with $\mathrm{PV}$, differences for men and women pooled or for men were statistically significant $(\mathrm{P}=0.003$ or $\mathrm{P}=0.0037$; $\mathrm{P}=0.17$ for women by the Wilcoxon test). In the corresponding comparison between $\mathrm{MM}$ and $\mathrm{PV}$, means $\pm \mathrm{SD}$ were statistically similar $(\mathrm{P}=0.23, \mathrm{P}=0.30, \mathrm{P}=$ 0.18 by the Wilcoxon test). Men with myeloma constituted the only subgroup of patients with an average maximum diameter greater than $10 \mathrm{~mm}$ (Figure 3).
The existence of a difference between the patients' group and the control group is reinforced by considering the macronodules (nodules of max diameter $>10 \mathrm{~mm}$ ). These were detected in 6 of the 18 women in the all malignancy group $v s .31$ of the 55 in the control group ( $33.3 \%$ vs. $\left.56.4 \% ; \chi^{2}=2.88, \mathrm{P}=0.089\right)$, and in $6 / 16$ vs. $27 / 30$ in the corresponding comparison for men ( $37.5 \%$ vs. $\left.76.7 \% ; \chi^{2}=6.87, \mathrm{P}=0.0087\right)$. Overall, thyroid nodules $>10 \mathrm{~mm}$ in max diameter were detected in $12 / 34$ patients vs. $58 / 85\left(35.3 \%\right.$ vs. $68.2 \% ; \chi^{2}=$ $10.88, \mathrm{P}=0.001)$. Of note, neither micro- nor macro-nodules were detected in the CML subgroup.

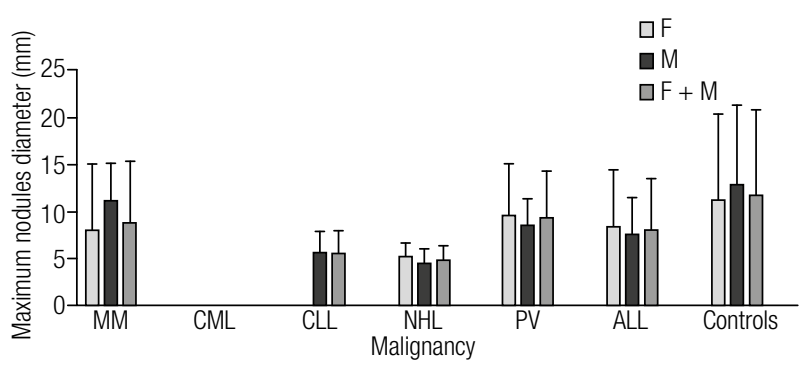

Figure 3. Maximum diameter of thyroid nodules in patients, excluding those with previously known thyroid diseases, and controls (none of whom had previously known thyroid disease). MM: multiple myeloma; CML: chronic myeloid leukemia; CLL: chronic lymphatic leukemia; NHL: nonHodgkin lymphoma; PV: polycythemia vera. 


\section{DISCUSSION}

In the last years an improvement in the outcome of patients affected by hematological malignancies has been observed, with long-term survival now expected for most patients (33). Even if thyroid disease is not a cause of mortality in these patients, it requires evaluation and intervention during their follow-up. In the present study, we have investigated thyroid complications after medical therapy alone in patients affected by hematological malignancies. Indeed, since external radiation in the head and neck region may damage thyroid function and favor the development of thyroid nodules (14), we have excluded patients who received previous or current external head/neck radiotherapy.

Overall, we found a low prevalence of enlarged thyroid (goiter), with none of our male patients being affected by it, and low prevalence of sonographic evidence of thyroiditis. Concerning ultrasonography-detected thyroiditis, the female preponderance over males is maintained with a ratio of $2: 1$. There were differences within the hematological malignancies. Goiter was detected only in MM and PV. Ultrasonographic evidence of thyroiditis was noted only in MM and NHL, the latter featuring the peak of frequency $(25 \%$, in women). The rate of ultrasonographic detection of thyroid nodules was the highest in MM (with a remarkable 100\% in women) and PV, and the lowest in the group of leukemias taken as a whole $(2 / 10=20 \%)$. Women with PV had the highest density of nodules (almost 7 nodules per patient) while men with PV or NHL have the lowest density ( $<2$ nodules per patient). Patients of either gender with NHL had the smallest thyroid nodules (maximum diameter consistently $<7 \mathrm{~mm}$ ). The almost refractoriness of chronic myeloid/lymphatic leukemia to be associated with diffuse goiter/thyroid nodules/thyroid autoimmune diseases is in line with the fact that none of our 10 patients with previously known thyroid disease belonged to the leukemia group. Excluding the $10 \mathrm{pa}-$ tients with previously known thyroid disease, overt or borderline derangement in thyroid function is restricted to MM patients who were treated with thalidomide or lenalidomide. The subnormal low TSH coexisting with FT3 on the lower normal side and FT4 in the upper normal side that we observed in four MM patients would suggest that the low T3 syndrome associated with the nonthyroid illness (NTI) status might have contributed to an FT4-oriented as opposed to the FT3-oriented subclinical hyperthyroidism. However, the NTI status per se can be associated with subnormal TSH levels, as a result of an increased secretion of cytokines (30). As discussed in two recent reviews $(5,31)$ both hyperthyroidism and hypothyroidism have been reported in association with thalidomide/lenalidomide therapy - two immunomodulatory drugs that induce endogenous cytokine release. Finally, these immunomodulatory drugs may induce an autoimmune damage to the thyroid through either direct effects on T-lymphocytes or deregulation of cytokines (5). In brief, also taking into account the retrospective nature of our study, we cannot attribute the thyroid biochemical picture of those four MM patients to NTI, thalidomide/lenalidomideinduced subclinical hyperthyroidism or both.

The very low prevalence of autoimmune thyroiditis (both by serological criteria and ultrasonographic criteria) is particularly striking, considering the high prevalence of HT in our province. This high prevalence was independently confirmed both in an endocrine division setting (29) and thyroid cytology setting $(34,35)$. More recently, this prevalence - though at lower levels - was confirmed in Catania, our neighbouring province (36). Consistent with this very low prevalence of AITD is the absence of a small thyroid (atrophic variant of HT), which in patients from the provinces of Messina and Catania account for 5.9 and $3.4 \%$ of the corresponding cohorts of HT patients (36). Consistent is also the very low prevalence of thyroid hypofunction, which accounts for 42.8 and $45.7 \%$ of the corresponding cohorts of Hashimoto's patients (36). Screening throughout the world shows that, in the elderly, subclinical hypothyroidism affects approximately 1 in 5 persons (37), which is in keeping with the prevalence we found in our controls. A close and long follow-up of our patients with hematological malignancies is needed to verify whether Hashimoto's thyroiditis is rare because they are somehow protected or because its onset is somehow delayed.

In summary, in patients treated for hematological malignancies in whom the variable of external irradiation has been excluded, we have found a significantly lower prevalence of thyroid abnormalities with respect to controls. In particular, a significantly lower prevalence of abnormal sonographic size and echotexture and a lower presence of nodularity were found in patients compared to controls. Women with NHL are those with the relatively highest prevalence of sonographic evidence of thyroiditis, while women with multiple myeloma and patients of either gender with 
PV have almost always thyroid nodules. Moreover, subclinical abnormalities in thyroid function were significantly less frequent in patients as a whole. Myeloma patients constituted the only subgroup of patients with a relatively great presence of abnormal sonographic and functional abnormalities.

\section{Study limitations}

One limitation of our study is that we lack biochemical and ultrasonographic data before chemotherapy. However, prevalence of thyroid dysfunction and thyroid autoimmunity is directly age-related and, once either is present, it progresses $(38,39)$. Therefore, the low rate of thyroid dysfunction and AITD we found in patients after an average of few years from the beginning of chemotherapy equates to a low rate also more years earlier, when chemotherapy was about to be started. The possibility of thyroid dysfunction or AITD that vanished spontaneously as the patient aged is untenable. The same reasoning applies to thyroid nodules, whose rate of spontaneous shrinkage or disappearance is very low, and especially valid for small cystic nodules (reabsorption of the liquid component) (40).

Strengths of the study are to have evaluated three thyroid aspects (nodularity, function and autoimmunity) simultaneously, at an interval of time from the end of chemotherapy sufficiently long to permit exclusion of transient changes, and in patients stratified based on the type of malignancy and gender.

Disclosure: no potential conflict of interest relevant to this article was reported.

\section{REFERENCES}

1. Swerdlow SH, Campo E, Harris NL, Jaffe ES, Pileri SA, Stein H, et al. WHO classification of tumours of haematopoietic and lymphoid tissues, fourth edition. International Agency for Research on Cancer (IARC), 2008. Lyon, France.

2. Sant M, Allemani C, Tereanu C, De Angelis R, Capocaccia R, Visser $O$, et al.; HAEMACARE Working Group. Incidence of hematologic malignancies in Europe by morphologic subtype: results of the HAEMACARE project. Blood. 2010;116(19):3724-34.

3. Bay JO, Guièze R, Ravinet A, Lemal R, Xhaard A, Bailly $S$, et al. [Major therapeutic advances and new perspectives in onco-hematology]. Bull Cancer. 2013;100(6):587-99.

4. Segler A, Tsimberidou AM. Lenalidomide in solid tumors. Cancer Chemother Pharmacol. 2012;69(6):1393-406.

5. Hamnvik OP, Larsen PR, Marqusee E. Thyroid dysfunction from antineoplastic agents. J Natl Cancer Inst. 2011;103(21):1572-87.

6. Figaro MK, Clayton W Jr, Usoh C, Brown K, Kassim A, Lakhani VT, et al. Thyroid abnormalities in patients treated with lenalidomide for hematological malignancies: results of a retrospective case review. Am J Hematol. 2011;86(6):467-70.
7. Stein EM, Rivera C. Transient thyroiditis after treatment with lenalidomide in a patient with metastatic renal cell carcinoma. Thyroid. 2007;17(7):681-3.

8. Badros AZ, Siegel E, Bodenner D, Zangari M, Zeldis J, Barlogie $B$, et al. Hypothyroidism in patients with multiple myeloma following treatment with thalidomide. Am J Med. 2002;112(5):412-3.

9. Chowta MN, Chowta NK. Hypothyroidism caused by thalidomide. Indian J Med Sci. 2006;60(10):424-6.

10. De Savary N, Lee R, Vaidya B. Severe hypothyroidism after thalidomide treatment. J R Soc Med. 2004;97(9):443.

11. Torino F, Corsello SM, Longo R, Barnabei A, Gasparini G. Hypothyroidism related to tyrosine kinase inhibitors: an emerging toxic effect of targeted therapy. Nat Rev Clin Oncol. 2009;6(4):219-28.

12. Torino F, Corsello SM, Longo R, Barnabei A, Gasparini G. Is hypothyroidism a clinically relevant toxicity of tyrosine kinase inhibitors? Thyroid. 2009;19(5):539-40.

13. Fallahi P, Ferrari SM, Vita R, Di Domenicantonio A, Corrado A, Benvenga $S$, et al. Thyroid dysfunctions induced by tyrosine kinase inhibitors. Expert Opin Drug Saf. 2014;13(6):723-33.

14. Jereczek-Fossa BA, Alterio D, Jassem J, Gibelli B, Tradati N, Orecchia R. Radiotherapy-induced thyroid disorders. CancerTreat Rev. 2004;30(4):369-84.

15. Klopper JP, Kane MA, Haugen BR. Anaplastic thyroid cancer and miscellaneous tumors of the thyroid. In: Braverman LE, Cooper DS, eds. Werner and Ingbar's the thyroid: a fundamental and clinical text. $10^{\text {th }}$ ed. Philadelphia: Lippincott Williams and Wilkins; 2013. p. 765-74.

16. Stein SA, Wartofsky L. Primary thyroid lymphoma: a clinical review. J Clin Endocrinol Metab. 2013;98(8):3131-8.

17. Hou Z, Zhu HL, Liu T. [Effects of imatinib mesylate on the levels of endocrine hormones]. Zhonghua Xue Ye Xue Za Zhi. 2013;34(9):762-6.

18. Zygulska AL, Krzemieniecki K, Sowa-Staszczak A. Hypothyroidism during treatment with tyrosine kinase inhibitors. Endokrynol Pol. 2012;63(4):302-6.

19. Kim TD, Schwarz M, Nogai $H$, Grille P, Westermann J, Plöckinger $U$, et al. Thyroid dysfunction caused by second-generation tyrosine kinase inhibitors in Philadelphia chromosome-positive chronic myeloid leukemia. Thyroid. 2010;20(11):1209-14.

20. de Diego García P, Trincado Aznar P, Playán Usón J, Albero Gamboa R. Levothyroxine therapy and imatinib. Endocrinol Nutr. 2008;55(7):304-7.

21. de Groot JW, Zonnenberg BA, Plukker JT, van Der GraafWT, Links TP. Imatinib induces hypothyroidism in patients receiving levothyroxine. Clin PharmacolTher. 2005;78(4):433-8.

22. Dora JM, Leie MA, Netto B, Fogliatto LM, Silla L, Torres F, et al. Lack of imatinib-induced thyroid dysfunction in a cohort of nonthyroidectomized patients. Eur J Endocrinol. 2008;158(5):771-2.

23. Braun D, Kim TD, le Coutre P, Köhrle J, Hershman JM, Schweizer $\mathrm{U}$. Tyrosine kinase inhibitors noncompetitively inhibit MCT8mediated iodothyronine transport. J Clin Endocrinol Metab. 2012;97(1):E100-5.

24. Yoshizato T, Nannya Y, Yoshiki Y, Nakamura F, Imai Y, Ichikawa M, et al. Nilotinib-induced hypothyroidism in a patient with chronic myeloid leukemia. Int J Hematol. 2011;93(3):400-2.

25. Mannavola D, Coco P, Vannucchi G, Bertuelli R, Carletto M, Casali $P G$, et al. A novel tyrosine-kinase selective inhibitor, sunitinib, induces transient hypothyroidism by blocking iodine uptake. J Clin Endocrinol Metab. 2007;92(9):3531-4.

26. Kaklamanos M, Thomas D, Pikazis D, Christaki S, Kaltsas G. The effect of rituximab on thyroid function and autoimmunity. 2013;23(8):1044-5.

27. Raterman HG, Simsek S, Lems WF, Meesters EW, Dijkmans BA, Nurmohamed MT. Rituximab and thyroid function. Arch Intern Med. 2009;169(11):1073-4. 
28. Soh SB, Pham A, O'Hehir RE, Cherk M, Topliss DJ. Novel use of rituximab in a case of Riedel's thyroiditis refractory to glucocorticoids and tamoxifen. J Clin Endocrinol Metab. 2013;98(9):3543-9.

29. Benvenga S, Trimarchi F. Changed presentation of Hashimoto's thyroiditis in North-Eastern Sicily and Calabria (Southern Italy) based on a 31-year experience. Thyroid. 2008;18(4):429-41.

30. Economidou F, Douka E, Tzanela M, Nanas S, Kotanidou A. Thyroid function during critical illnesses. Hormones (Athens). 2011;10(2):117-24.

31. Łacka K, Fraczek MM. Classification and etiology of hyperthyroidism. Pol Merkur Lekarski. 2014;36(213):206-11.

32. Wiersinga WM, van den Berghe G. Nonthyroidal illness syndrome. In: Braverman LE, Cooper DS, eds. Werner and Ingbar's the thyroid: a fundamental and clinical text. $10^{\text {th }}$ ed. Philadelphia: Lippincott Williams and Wilkins; 2013. p. 203-17.

33. Izar B, Rotow J, Gainor J, Clark J, Chabner B. Pharmacokinetics, clinical indications, and resistance mechanisms in molecular targeted therapies in cancer. Pharmacol Rev. 2013;65(4):1351-95.

34. Rizzo M, Sindoni A, Talamo Rossi R, Bonaffini O, Panetta S, Scisca $C$, et al. Annual increase in the frequency of papillary thyroid carcinoma as diagnosed by fine-needle aspiration at a cytology unit in Sicily. Hormones (Athens). 2013;12(1):46-57.
35. Rizzo M, Rossi RT, Bonaffini O, Scisca C, Altavilla G, Calbo L, et al. Increased annual frequency of Hashimoto's thyroiditis between years 1988 and 2007 at a cytological unit of Sicily. Ann Endocrinol (Paris). 2010;71(6):525-34.

36. Latina A, Gullo D, Trimarchi F, Benvenga S. Hashimoto's thyroiditis: similar and dissimilar characteristics in neighboring areas. Possible implications for the epidemiology of thyroid cancer. PLoS One. 2013;8(3):e55450.

37. Surks MI, Ortiz E, Daniels GH, Sawin CT, Col NF, Cobin RH, et al. Subclinical thyroid disease: scientific review and guidelines for diagnosis and management. JAMA. 2004;291(2):228-38.

38. Boucai $L$, Surks Ml. Age related changes in thyroid function. In: Braverman LE, Cooper DS, eds. Werner and Ingbar's the thyroid: a fundamental and clinical text. $10^{\text {th }}$ ed. Philadelphia: Lippincott Williams and Wilkins; 2013. p. 183-7.

39. Weetman AP. Chronic autoimmune thyroiditis. In: Braverman LE, Cooper DS, eds. Werner and Ingbar's the thyroid: a fundamental and clinical text. $10^{\text {th }}$ ed. Philadelphia: Lippincott Williams and Wilkins; 2013. p. 525-35.

40. Mandel SJ, Langer JE, Kaplan MM. Clinical evaluation and management of thyroid nodules. In: Braverman LE, Cooper DS, eds. Werner and Ingbar's the thyroid: a fundamental and clinical text. $10^{\text {th }}$ ed. Philadelphia: Lippincott Williams and Wilkins; 2013. p. 649-64. 